\title{
Erratum to: Efficacy of intraarticular application of ketamine or ketamine-levobupivacaine combination on post-operative pain after arthroscopic meniscectomy
}

\author{
Cengiz Isik • Abdullah Demirhan • \\ Tevfik Yetis · Korgun Okmen · Hakan Sarman • \\ Umit Yasar Tekelioglu • Turan Duran
}

Published online: 31 August 2014

(C) European Society of Sports Traumatology, Knee Surgery, Arthroscopy (ESSKA) 2014

Erratum to: Knee Surg Sports Traumatol Arthrosc

DOI 10.1007/s00167-014-2962-0

Unfortunately, the fourth author's family name was incorrect in the original publication. The correct family name is Okmen. The complete author group is given here.

Cengiz Isik · Abdullah Demirhan · Tevfik Yetis · Korgun Okmen · Hakan Sarman · Umit Yasar Tekelioglu · Turan Duran.

The online version of the original article can be found under doi:10.1007/s00167-014-2962-0.

C. Isik $(\bowtie) \cdot H$. Sarman

Department of Orthopedics and Traumatology, Faculty of Medicine, Abant İzzet Baysal University Medical School, Abant İzzet Baysal University, 14280 Gölköy, Bolu, Turkey e-mail: drcengiz034@yahoo.com

A. Demirhan · U. Y. Tekelioglu

Department of Anesthesiology and Reanimation, Faculty of

Medicine, Abant Izzet Baysal University, Bolu, Turkey

T. Yetis $\cdot$ T. Duran

Department of Orthopedics and Traumatology,

Bolu Izzet Baysal State Hospital, Bolu, Turkey

K. Okmen

Department of Anesthesiology and Reanimation,

Bolu Izzet Baysal State Hospital, Bolu, Turkey 